\title{
KEPATUHAN TERHADAP SOP KETINGGIAN PADA PEKERJA KONSTRUKSI
}

\author{
COMPLIANCE TOWARD SOP OF HEIGHT AT CONSTRUCTION WORKER
}

\author{
Fhanin Dyanita \\ PT. Multi Brata Anugrah Utama \\ E-mail: fhanindyanita@yahoo.com
}

\begin{abstract}
Implementing SOP (Standard and Operational Procedures) is one of the efforts to protect workers from occupational hazards, especially for high risk jobs such as working at height. The purpose of this research is to analyze the correlation of knowledge, personality, communication, and safety supervision toward compliance of working at height's SOP at PT Sri Murni worker in Tunjungan Plaza 6 construction project. This research is analytic observational with cross sectional design. The subject of this study were the sample of workers taken using simple random sampling and obtained the number of 33 respondents. The available data have been presented in the form of frequency distribution and cross tabulation, then analyzed statistically by chi square. The results showed that most workers was compliance with working at height's SOP. The results of statistical analysis showing that knowledge $(p=0.010, r=0.447)$ and communications $(p=0.016$, $r=0.418$ ) as factors that significantly related to working at height's SOP and have moderate relations. Personality $(p=0.656)$ and safety supervision $(p=0.464)$ were not related to working at height's SOP compliance. The conclusion of this research is compliance of SOP have correlation with knowledge, personality, communication, and safety supervision. Suggestion to the company based on the results of research are to increase worker's knowledge through safety talk or training, and the safety man to pay more attention to workers while they are doing working at height's job so they could more compliance to SOP. Company should also provide PPE as much as the number of workers.
\end{abstract}

Keywords: standard and operational procedures, compliance, working at height, construction

\begin{abstract}
ABSTRAK
Menerapkan SOP (Standar dan Operasional Prosedur) merupakan salah satu upaya untuk melindungi pekerja dari bahaya kecelakaan kerja, terutama untuk pekerjaan dengan risiko tinggi seperti pekerjaan yang dilakukan di ketinggian. Tujuan penelitian ini adalah menganalisis hubungan antara pengetahuan, kepribadian, komunikasi, dan pengawasan pihak safety dengan kepatuhan pekerja PT Sri Murni terhadap SOP bekerja di ketinggian di proyek konstruksi Tunjungan Plaza 6 Surabaya. Jenis penelitian ini adalah observasional analitik dengan desain cross sectional. Subyek penelitian ini adalah sampel pekerja yang diambil menggunakan rumus simple random sampling dan didapatkan jumlah 33 responden. Data yang tersedia disajikan dalam bentuk distribusi frekuensi dan tabulasi silang kemudian dianalisis secara statistik chi square. Hasil penelitian menunjukkan bahwa sebagian besar pekerja patuh terhadap SOP bekerja di ketinggian. Hasil analisis statistik menunjukkan bahwa pengetahuan $(p=0,010 ; r=0,447)$ dan komunikasi $(p=0,016 ; r=0,418)$ sebagai faktor yang berhubungan signifikan dengan kepatuhan SOP bekerja di ketinggian dan memiliki kuat hubungan sedang. Kepribadian $(\mathrm{p}=0,656)$ dan pengawasan HSE atau pihak safety $(\mathrm{p}=0,464)$ tidak berhubungan dengan kepatuhan SOP bekerja di ketinggian. Kesimpulan dari penelitian ini adalah kepatuhan dipengaruhi oleh pengetahuan, kepribadian, komunikasi, dan pengawasan pihak safety. Saran berdasarkan hasil penelitian kepada perusahaan adalah meningkatkan pengetahuan bagi pekerja melalui safety talk atau training, dan pihak HSE atau safety agar lebih mengawasi pekerja saat melakukan pekerjaan agar para pekerja lebih patuh terhadap SOP. Perusahaan juga sebaiknya menyediakan APD sesuai dengan jumlah pekerja.
\end{abstract}

Kata kunci: standar dan operasional prosedur, kepatuhan, bekerja di ketinggian, konstruksi

\section{PENDAHULUAN}

Era globalisasi sekarang, pembangunan industri berkembang sangat pesat. Salah satunya adalah industri konstruksi, industri konstruksi adalah industri yang menyediakan jasa konstruksi sehingga mempunyai peran yang cukup signifikan terhadap pembangunan yang ada saat ini. Namun pekerjaan di bidang konstruksi memiliki risiko bahaya yang cukup tinggi karena berbagai faktor 
diantaranya pekerjaan yang berubah-ubah, pekerja yang beragam, juga kondisi lingkungan kerja yang dinamis. Tingginya risiko bahaya yang ada harus diimbangi dengan upaya keselamatan dan kesehatan pada tenaga kerja di tempat kerja.

Keselamatan dan kesehatan kerja (K3) merupakan suatu promosi dan peningkatan tingkat fisik, mental, dan kesejahteraan dari setiap pekerjaan, mencegah pekerja dari penyakit akibat kerja, melindungi pekerja dari risiko dan faktor-faktor yang dapat mengganggu kesehatan, menempatkan dan mengatur pekerja untuk beradaptasi dengan lingkungannya dan untuk mempermudah adaptasi pekerja terhadap pekerjaannya masing-masing. Semua elemen dalam konstruksi memiliki kontribusi dalam upaya keselamatan kerja. Upaya K3 diharapkan dapat meminimalisir risiko terjadinya penyakit akibat kerja dan kecelakaan di tempat kerja agar tenaga kerja dapat bekerja dengan aman. Salah satu cara untuk meminimalisir risiko kecelakaan kerja yang mungkin dapat terjadi yaitu dengan menerapkan pengendalian bahaya yang terdiri dari eliminasi, substitusi, teknik, administrasi, dan APD.

Pekerjaan yang dilakukan di sektor konstruksi merupakan pekerjaan yang berbahaya dan memiliki kemungkinan besar untuk terjadi kecelakaan. Kecelakaan kerja di tempat kerja menimbulkan banyak kerugian diantaranya kerugian materi, korban jiwa, serta terganggunya proses produksi. Risiko bahaya yang ada dalam kegiatan konstruksi sangat beragam diantaranya proses pengangkatan bendabenda berat, pekerjaan di ruang yang terbatas, dan juga pekerjaan di ketinggian. Salah satu pekerjaan yang mempunyai risiko tinggi adalah pekerjaan di ketinggian.

Banyak hal yang perlu diperhatikan saat akan melakukan pekerjaan di ketinggian untuk meminimalkan risiko terjadinya kecelakaan misalnya penggunaan APD (Full Body Harness), kepatuhan terhadap prosedur yang ada, dan scaffolding yang aman untuk digunakan. Namun banyak pekerja yang sering mengabaikan penggunaan peralatan pelindung yang sesuai dengan SOP dan telah diatur dalam pedoman K3 konstruksi. Data pelanggaran terhadap prosedur bekerja di ketinggian yang meningkat secara signifikan sebesar $140 \%$ pada tahun 2010 dan 2011 (Zalaya, 2012). Data kasus pelanggaran prosedur kerja dan kecelakaan kerja di ketinggian di Indonesia pada tahun 2010 hingga 2011 pada Tabel 1.
Tabel 1. Data Kasus Pelanggaran SOP dan Kecelakaan Kerja di Indonesia

\begin{tabular}{lcc}
\hline \multicolumn{1}{c}{ Kasus } & Tahun 2010 & Tahun 2011 \\
\hline Pelanggaran SOP & 27 & 65 \\
$\begin{array}{l}\text { Kecelakaan kerja di } \\
\text { ketinggian }\end{array}$ & 7 & 10 \\
\hline
\end{tabular}

Pelanggaran tersebut menunjukkan bahwa masih banyak tenaga kerja yang belum mematuhi prosedur bekerja di ketinggian. Oleh karena itu diperlukan penelitian lebih lanjut untuk mengetahui faktor-faktor yang membuat tenaga kerja menjadi patuh dalam melaksanakan standar operasional prosedur bekerja di ketinggian.

Teori safety triad yang dikemukakan oleh Geller (2001) menjelaskan bahwa terdapat tiga komponen yang saling berhubungan dalam membentuk budaya selamat, komponen-komponen tersebut yaitu people (orang), behavior (perilaku), dan environment (lingkungan). Faktor-faktor yang termasuk dalam komponen people seperti pengetahuan, kemampuan, motivasi, kepandaian, kepribadian, dan keterampilan. Beberapa faktor dalam komponen behavior antara lain komunikasi, kepedulian, persetujuan, dan pelatihan. Sedangkan faktorfaktor yang terdapat dalam komponen environment adalah suhu, peralatan, dan perlengkapan, mesin, dan standar operasional prosedur. Geller (2001) menjelaskan dalam teori safety triad standar dan operasional prosedur termasuk dalam komponen environment yang berhubungan dengan faktor-faktor dalam komponen people dan behavior. Kepatuhan (compliance) dalam teori safety triad merupakan salah satu faktor komponen behavior. Oleh karena itu, penelitian ini dilakukan untuk membuktikan faktor-faktor yang berhubungan dengan kepatuhan tenaga kerja terhadap SOP (Standar Operasional Prosedur) berdasarkan konsep safety triad.

Bekerja di ketinggian memiliki risiko bahaya yang cukup tinggi, sehingga perlu diterapkan standar operasional prosedur yang mengatur tentang bekerja di ketinggian. Adanya standar operasional prosedur tersebut bertujuan untuk melindungi tenaga kerja dari risiko bahaya yang mungkin terjadi selama melakukan pekerjaan. Walaupun telah terdapat standar operasional prosedur tapi masih tetap ada beberapa kecelakaan saat melakukan pekerjaan di ketinggian. Jatuh dari ketinggian merupakan penyumbang terbesar dalam kecelakaan kerja di ketinggian. Terdapat 126 kejadian jatuh dari 
ketinggian pada tahun 1998 hingga tahun 2008 (Workplace Safety and Health Council, 2011).

Surabaya merupakan salah satu kota besar di Indonesia, sehingga setiap waktu pembangunan gedung perkantoran, tempat tinggal, pusat perbelanjaan dan sebagainya terus bertambah. Banyaknya pembangunan gedung di kota Surabaya mengakibatkan bertambah besarnya risiko kecelakaan kerja di bidang konstruksi. Pembangunan gedung Tunjungan Plaza 6 merupakan salah satu dari beberapa pembangunan pusat perbelanjaan di Surabaya. PT Sri Murni sebagai salah satu subkontraktor di proyek pembangunan Tunjungan Plaza 6 yang menangani pemasangan kaca. Pekerjaan pemasangan kaca merupakan pekerjaan yang dilakukan di ketinggian dan mempunyai potensi bahaya besar, sehingga diperlukan adanya SOP yang harus dipatuhi oleh tenaga kerja dalam rangka mengendalikan risiko kecelakaan yang mungkin terjadi. Namun berdasarkan observasi dan wawancara yang dilakukan dengan pihak HSE PT. Sri Murni ditemukan beberapa pekerja yang tidak mematuhi SOP seperti tidak menggunakan full body harness dan melakukan pekerjaan di scaffolding yang tidak aman. Ketidakpatuhan pekerja ini merupakan masalah karena pekerjaan yang dilakukan merupakan pekerjaan dengan risiko tinggi. Kecelakaan kerja disebabkan oleh tiga faktor menurut An Investigation of Managements Commitment to Construction Safety Journal yaitu kurangnya komitmen dan kepemimpinan manajemen, kondisi bekerja yang aman, kebiasaan kerja yang aman. Kebiasaan kerja yang aman contohnya adalah kepatuhan tenaga kerja terhadap standar dan prosedur kerja yang ada. Berdasarkan teori dan data kecelakaan kerja jatuh dari ketinggian yang telah dipaparkan, diperlukan penelitian lebih lanjut untuk menganalisis faktorfaktor yang berhubungan dengan kepatuhan tenaga kerja terhadap standar dan operasional prosedur bekerja di ketinggian sesuai dengan teori safety triad. Tujuan umum dari penelitian ini adalah untuk menganalisis faktor yang berhubungan dengan kepatuhan terhadap standar dan operasional prosedur pada pekerja pemasangan kaca PT. Sri Murni di proyek konstruksi Tunjungan Plaza 6 Surabaya.

\section{METODE}

Jenis penelitian yang digunakan dalam penelitian ini adalah observasional karena hanya melakukan pengamatan tanpa memberikan perlakuan pada objek penelitian. Berdasarkan lokasi pelaksanaan, penelitian ini termasuk penelitian lapangan. Penelitian ini menggunakan desain penelitian cross sectional karena pengamatan dilakukan pada suatu periode tertentu.

Populasi penelitian adalah semua tenaga kerja pemasangan kaca PT. Sri Murni proyek konstruksi Tunjungan Plaza 6 Surabaya yang berjumlah 50 orang. Sampel dalam penelitian ini adalah sebagian pekerja pemasangan kaca PT. Sri Murni di proyek konstruksi Tunjungan Plaza 6 Surabaya sebanyak 33 responden. Metode pengambilan sampel dalam penelitian ini menggunakan rumus simple random sampling.

Penelitian ini dilakukan di proyek konstruksi Tunjungan Plaza 6 Surabaya. Waktu penelitian ini dimulai Desember 2016-Maret 2017. Pengumpulan data pada Februari dan Maret 2017. Variabel bebas dalam penelitian ini adalah pengetahuan, kepribadian, komunikasi, dan pengawasan pihak safety. Variabel terikatnya adalah kepatuhan terhadap pekerja terhadap SOP bekerja di ketinggian.

Pengambilan data dilakukan dengan cara wawancara menggunakan kuesioner yang meliputi variabel pengetahuan, kepribadian, pelatihan penerapan SOP, komunikasi, pengawasan HSE, ketersediaan APD, dan kepatuhan terhadap SOP. Responden mengisi kuesioner didampingi oleh peneliti atau enumerator yang telah dilatih dengan melakukan role play dan brainstorming agar enumerator memiliki pemahaman yang sama seperti yang dimaksud peneliti. Sebelum mengisi kuesioner, peneliti atau enumerator menjelaskan secara singkat kepada responden tentang penelitian tersebut. Responden yang bersedia menjadi subjek penelitian kemudian mengisi informed consent. Pengambilan data juga dilakukan dengan cara wawancara langsung kepada supervisor atau HSE di proyek konstruksi tersebut bertujuan untuk mendapatkan informasi yang lebih detail terkait kepatuhan SOP bekerja di ketinggian. Pengambilan data sekunder diperoleh melalui data dari perusahaan yang meliputi gambaran umum perusahaan, jumlah tenaga kerja dan tentang standar dan operasional prosedur bekerja di ketinggian.

Data yang telah terkumpul kemudian diolah dengan mengecek kelengkapan instrumen tentang variabel yang diteliti kemudian dianalisa secara univariat dan bivariat. Hasil analisa data univariat disajikan dalam bentuk distribusi frekuensi disertai narasi, sedangkan hasil analisa data bivariat akan disajikan dalam bentuk tabulasi silang. Uji analisa data bivariat yang digunakan adalah chi square test 
Tabel 2. Koefisien Kontingensi

\begin{tabular}{cc}
\hline Interval Koefisien & Kuat Hubungan \\
\hline $0,00-0,199$ & Sangat rendah \\
$0,20-0,399$ & Rendah \\
$0,40-0,599$ & Sedang \\
$0,60-0,699$ & Kuat \\
$0,70-0,799$ & Sangat Kuat \\
\hline
\end{tabular}

Sumber: Dahlan, 2001

dan apabila hasil analisa data menyatakan bahwa hipotesis diterima maka akan diuji kuat hubungan melalui koefisien kontingensi. Interval koefisien kontingensi dan kuat hubungan dapat dilihat pada tabel 2.

Setelah data dianalisis, langkah selanjutnya adalah melakukan penarikan kesimpulan.

\section{HASIL}

\section{Gambaran Umum Tempat Penelitian}

PT Sri Murni adalah distributor alumunium ekstrusi dan retail yang berlokasi di Surabaya, Indonesia. PT Sri Murni adalah spesialis dalam mendistribusikan alumunium ekstrusi, alumunium komposit panel, dan aksesori. Dengan pengalaman lebih dari dua puluh lima tahun dalam memasok dan mendistribusikan bahan dan produk alumunium. Perusahaan ini didirikan pada tahun 1980, dengan outlet pertama yang berlokasi di Jalan Ngaglik XVII/17. PT Sri Murni saat ini sudah memiliki tiga gerai dan empat gudang. PT Sri Murni juga memiliki cabang yaitu Alflex Megah yang berada di Jakarta.

PT Sri Murni memiliki visi dan misi yaitu untuk menyediakan produk berkualitas tinggi dan harga bersaing, sehingga menjadi salah satu distributor ekstrusi alumunium terkemuka di Indonesia. Hal tersebut sesuai dengan motto PT Sri Murni "Trust Us, We Deliver".

\section{Distribusi Pengetahuan Pekerja}

Pengetahuan dalam penelitian ini dikategorikan ke dalam dua kategori yaitu baik dan kurang. Distribusi responden berdasarkan pengetahuan pada pekerja pemasangan kaca PT Sri Murni di proyek konstruksi Tunjungan Plaza 6 Surabaya dapat dilihat pada tabel 3.

Berdasarkan data distribusi pengetahuan tentang Standar dan Operasional Prosedur pada pekerja
Tabel 3. Distribusi Pengetahuan Pekerja Pemasangan Kaca PT Sri Murni

\begin{tabular}{ccc}
\hline Pengetahuan & Frekuensi & Persentase \\
\hline Baik & 22 & 66,7 \\
Kurang & 11 & 33,3 \\
\hline Jumlah Total & 33 & 100,0 \\
\hline
\end{tabular}

Tabel 4. Distribusi Kepribadian Pekerja Pemasangan Kaca PT Sri Murni

\begin{tabular}{ccc}
\hline Kepribadian & Frekuensi & Persentase \\
\hline Tipe A & 16 & 48,5 \\
Tipe B & 17 & 51,5 \\
\hline Total & 33 & 100,0 \\
\hline
\end{tabular}

pemasangan kaca PT Sri Murni di proyek konstruksi Tunjungan Plaza 6 Surabaya 2017 dapat dilihat bahwa mayoritas pekerja memiliki pengetahuan baik yaitu sebesar 66,7\% (22 dari 33). Pengetahuan dapat diperoleh dari pelatihan maupun dari safety talk. Kesimpulannya adalah mayoritas pekerja memiliki pengetahuan yang baik tentang SOP bekerja di ketinggian.

\section{Distribusi Kepribadian Pekerja}

Kepribadian pekerja dibagi menjadi dua tipe, yaitu kepribadian tipe A dan kepribadian tipe B. Distribusi responden berdasarkan tipe kepribadian pada pekerja pemasangan kaca PT Sri Murni di proyek konstruksi Tunjungan Plaza 6 Surabaya dapat dilihat pada tabel 4.

Berdasarkan data distribusi kepribadian pekerja pemasangan kaca PT Sri Murni di proyek konstruksi Tunjungan Plaza 6 Surabaya 2017 menyatakan bahwa $48,5 \%$ pekerja memiliki kepribadian dominan tipe A sedangkan 51,5\% pekerja memiliki kepribadian dominan tipe B. Jumlah pekerja yang memiliki kepribadian tipe A dan tipe B hampir seimbang.

\section{Distribusi Komunikasi Pekerja}

Komunikasi dalam penelitian ini dikategorikan menjadi dua kategori yaitu baik dan kurang. Distribusi responden berdasarkan komunikasi pada pekerja pemasangan kaca PT Sri Murni di proyek konstruksi Tunjungan Plaza 6 Surabaya dapat dilihat pada tabel 5 . 
Tabel 5. Distribusi Komunikasi Pekerja Pemasangan Kaca PT Sri Murni

\begin{tabular}{ccc}
\hline Komunikasi & Frekuensi & Persentase \\
\hline Baik & 21 & 63,6 \\
Kurang & 12 & 36,4 \\
\hline Total & 33 & 100,0 \\
\hline
\end{tabular}

Tabel 6. Distribusi Pengawasan HSE atau Pihak Safety PT Sri Murni

\begin{tabular}{ccc}
\hline Pengawasan & Frekuensi & Persentase \\
\hline Baik & 30 & 90,9 \\
Kurang & 3 & 9,1 \\
\hline Total & 33 & 100,0 \\
\hline
\end{tabular}

Berdasarkan data distribusi komunikasi pekerja pemasangan kaca PT Sri Murni di proyek konstruksi Tunjungan Plaza 6 Surabaya 2017 dapat dilihat bahwa mayoritas pekerja memiliki komunikasi yang baik yaitu sebesar 63,6\% (21 dari 33). Komunikasi yang dimaksud adalah komunikasi antar pekerja, pekerja dengan supervisor atau atasan, maupun dengan orang lain.

\section{Distribusi Pengawasan HSE atau Pihak Safety}

Pengawasan HSE atau pihak safety dibagi menjadi dua kategori yaitu baik dan kurang. Distribusi responden berdasarkan pengawasan HSE atau pihak safety pada pekerja pemasangan kaca PT Sri Murni di proyek konstruksi Tunjungan Plaza 6 Surabaya dapat dilihat pada tabel 6 .

Berdasarkan data distribusi di atas, mayoritas pekerja pemasangan kaca PT Sri Murni di proyek konstruksi Tunjungan Plaza 6 Surabaya 2017 menyatakan bahwa pihak HSE atau safety telah melakukan pengawasan dengan baik yaitu sebesar 90,9\%. Hal ini menunjukkan bahwa selama ini pihak HSE atau safety PT Sri Murni telah melakukan pengawasan yang baik terhadap pekerja.

\section{Distribusi Kepatuhan Pekerja}

Kepatuhan pekerja terhadap SOP bekerja di ketinggian didapatkan dengan cara checklist setiap komponen dalam SOP. Checklist dilakukan setelah melakukan observasi, wawancara, dan telaah dokumen atau data sekunder yang dibutuhkan untuk setiap komponen dalam SOP bekerja di ketinggian. Setelah itu didapatkan data yang kemudian dibagi menjadi dua kategori yaitu kategori patuh dan tidak
Tabel 7. Distribusi Kepatuhan Pekerja terhadap SOP

\begin{tabular}{ccc}
\hline Kepatuhan & Frekuensi & Persentase \\
\hline Patuh & 27 & 81,8 \\
Tidak Patuh & 6 & 18,2 \\
\hline Total & 33 & 100,0 \\
\hline
\end{tabular}

patuh. Pekerja dikategorikan patuh jika pekerja memenuhi dan melakukan semua komponen dalam SOP bekerja di ketinggian, sedangkan pekerja dikategorikan tidak patuh jika terdapat komponen dalam SOP bekerja di ketinggian yang tidak dilakukan oleh pekerja. Distribusi responden berdasarkan kepatuhan SOP bekerja di ketinggian pada pekerja pemasangan kaca PT Sri Murni di proyek konstruksi Tunjungan Plaza 6 Surabaya dapat dilihat pada tabel 7 .

Berdasarkan data distribusi kepatuhan pekerja pemasangan kaca PT Sri Murni terhadap SOP bekerja di ketinggian di proyek konstruksi Tunjungan Plaza 6 Surabaya 2017 menyatakan bahwa $81,8 \%$ patuh menerapkan SOP sedangkan $18,2 \%$ pekerja tidak patuh dalam menerapkan SOP bekerja di ketinggian.

\section{Analisis Bivariat}

\section{Hubungan Pengetahuan dengan Kepatuhan terhadap SOP}

Hubungan antara pengetahuan pekerja dengan kepatuhan terhadap SOP dapat dilihat pada tabel 8. Pekerja yang patuh SOP bekerja di ketinggian dan memiliki pengetahuan baik sebanyak 21 pekerja $(95,5 \%)$ sedangkan pekerja yang memiliki pengetahuan kurang dan patuh SOP bekerja di ketinggian sebanyak 6 pekerja $(54,5 \%)$. Berdasarkan hasil uji statistik chi square antara pengetahuan dengan kepatuhan SOP bekerja di ketinggian didapatkan signifikansi $0,010<\alpha$ sehingga diartikan terdapat hubungan antara pengetahuan dengan

Tabel 8. Tabulasi Silang antara Pengetahuan dengan Kepatuhan Pekerja

\begin{tabular}{cccc}
\hline \multirow{2}{*}{ Pengetahuan } & \multicolumn{2}{c}{ Kepatuhan } & \multirow{2}{*}{ Total } \\
\cline { 2 - 3 } & Patuh & Tidak Patuh & \\
\hline Baik & 21 & 1 & 22 \\
Kurang & 6 & 5 & 11 \\
\hline Total & 27 & 6 & 33 \\
\hline
\end{tabular}


Tabel 9. Tabulasi Silang antara Kepribadian dengan Kepatuhan Pekerja

\begin{tabular}{cccc}
\hline \multirow{2}{*}{ Kepribadian } & \multicolumn{2}{c}{ Kepatuhan } & \multirow{2}{*}{ Total } \\
\cline { 2 - 3 } & Patuh & Tidak Patuh & \\
\hline Tipe A & 14 & 2 & 16 \\
Tipe B & 13 & 4 & 17 \\
\hline Total & 27 & 6 & 33 \\
\hline
\end{tabular}

kepatuhan SOP bekerja di ketinggian. Setelah diketahui terdapat hubungan antara pengetahuan dengan kepatuhan SOP bekerja di ketinggian maka dilihat nilai koefisien kontingensi yaitu 0,447 . Jika dibandingkan dengan tabel 1 koefisien kontingensi, pengetahuan memiliki kuat hubungan yang sedang dengan kepatuhan pekerja terhadap SOP bekerja di ketinggian. Kesimpulannya adalah pekerja yang memiliki pengetahuan baik tentang SOP lebih patuh dalam menerapkan SOP bekerja di ketinggian daripada yang memiliki pengetahuan kurang tentang SOP bekerja di ketinggian.

\section{Hubungan Kepribadian dengan Kepatuhan terhadap SOP}

Pekerja yang patuh terhadap SOP bekerja di ketinggian dan memiliki kepribadian dominan tipe A sebanyak 14 pekerja (87,5\%) sedangkan pekerja yang patuh terhadap SOP bekerja di ketinggian dan memiliki kepribadian dominan tipe B sebanyak 13 pekerja $(76,5 \%)$ sehingga dapat disimpulkan bahwa pekerja dengan tipe kepribadian A lebih patuh terhadap SOP dibandingkan pekerja dengan tipe kepribadian B. Berdasarkan hasil uji statistik chi square antara kepribadian dengan kepatuhan SOP bekerja di ketinggian didapatkan signifikansi $0,656>\alpha$ sehingga diartikan tidak ada hubungan antara kepribadian dengan kepatuhan penerapan SOP bekerja di ketinggian

\section{Hubungan Komunikasi dengan Kepatuhan terhadap SOP}

Pekerja yang patuh terhadap SOP bekerja di ketinggian dan memiliki komunikasi baik sebanyak 20 pekerja $(95,2 \%)$ sedangkan pekerja yang patuh terhadap SOP bekerja di ketinggian dan memiliki komunikasi kurang sebanyak 7 pekerja $(58,3 \%)$. Berdasarkan hasil uji statistik chi square antara komunikasi dengan kepatuhan pekerja terhadap
Tabel 10.Tabulasi Silang antara Komunikasi dengan Kepatuhan Pekerja

\begin{tabular}{cccc}
\hline \multirow{2}{*}{ Komunikasi } & \multicolumn{2}{c}{ Kepatuhan } & \multirow{2}{*}{ Total } \\
\cline { 2 - 3 } & Patuh & Tidak Patuh & \\
\hline Baik & 20 & 1 & 21 \\
Kurang & 7 & 5 & 12 \\
\hline Total & 27 & 6 & 33 \\
\hline
\end{tabular}

SOP bekerja di ketinggian didapatkan signifikansi $0,016<\alpha$ sehingga diartikan terdapat hubungan antara komunikasi dengan kepatuhan SOP bekerja di ketinggian. Setelah diketahui terdapat hubungan antara komunikasi dengan kepatuhan SOP bekerja di ketinggian maka dilihat nilai koefisien kontingensi yaitu 0,418 . Jika dibandingkan dengan tabel 10koefisien kontingensi, komunikasi memiliki kuat hubungan yang sedang dengan kepatuhan pekerja terhadap SOP bekerja di ketinggian. Pekerja yang memiliki komunikasi baik tentang SOP lebih patuh dalam menerapkan SOP bekerja di ketinggian daripada yang memiliki komunikasi kurang.

\section{Hubungan Pengawasan HSE atau Pihak Safety dengan Kepatuhan SOP}

Pekerja yang mendapatkan pengawasan yang baik dari pihak safety dan patuh terhadap SOP bekerja di ketinggian sebanyak 25 pekerja $(83,3 \%)$ sedangkan pekerja yang mendapatkan pengawasan kurang dari pihak safety dan patuh terhadap SOP bekerja di ketinggian sebanyak 2 pekerja $(66,7 \%)$. Berdasarkan hasil uji statistik chi square antara pengawasan pihak safety dengan kepatuhan SOP bekerja di ketinggian didapatkan signifikansi sebesar $0,464>\alpha$ sehingga diartikan tidak ada hubungan antara pengawasan pihak safety dengan kepatuhan terhadap SOP bekerja di ketinggian.

Tabel 11.Tabulasi Silang antara Pengawasan HSE atau Pihak Safety dengan Kepatuhan Pekerja

\begin{tabular}{cccc}
\hline \multirow{2}{*}{ Pengawasan } & \multicolumn{2}{c}{ Kepatuhan } & \multirow{2}{*}{ Total } \\
\cline { 2 - 3 } & Patuh & Tidak Patuh & \\
\hline Baik & 25 & 5 & 30 \\
Kurang & 2 & 1 & 3 \\
\hline Total & 27 & 6 & 33 \\
\hline
\end{tabular}




\section{PEMBAHASAN}

\section{Pengetahuan}

Menurut teori safety triad, pengetahuan merupakan salah satu faktor dalam komponen person yang akan memengaruhi kepatuhan (Geller, 2001). Berdasarkan hasil penelitian yang dilakukan di proyek konstruksi Tunjungan Plaza 6 Surabaya dapat membuktikan hipotesis bahwa terdapat hubungan yang signifikan antara pengetahuan dengan kepatuhan terhadap SOP bekerja di ketinggian.

Pengetahuan memiliki hubungan yang signifikan dengan kepatuhan terhadap SOP bekerja di ketinggian dan memiliki nilai koefisien kontingensi 0,447 . Bila dibandingkan dengan tabel 8 tentang koefisien kontingensi, kuat hubungan antara pengetahuan dengan kepatuhan SOP bekerja di ketinggian adalah sedang. Hal ini berarti pengetahuan memiliki hubungan yang tidak lemah namun juga tidak begitu kuat dengan kepatuhan SOP bekerja di ketinggian. Terbukti pekerja yang berpengetahuan baik memiliki persentase lebih besar untuk patuh dalam menerapkan SOP bekerja di ketinggian daripada pekerja yang berpengetahuan kurang. Namun beberapa pekerja yang berpengetahuan rendah juga ada yang patuh terhadap SOP bekerja di ketinggian. Hal ini berarti pengetahuan memiliki hubungan dengan kepatuhan terhadap SOP bekerja di ketinggian namun tidak menjadi faktor utama yang membuat tenaga kerja patuh menerapkan SOP bekerja di ketinggian.

Hasil penelitian ini didukung oleh penelitian Judha (2012) yang menyatakan bahwa terdapat hubungan antara pengetahuan dengan kepatuhan SOP. Hasil penelitian Judha (2012) menyatakan bahwa pengetahuan yang baik berpeluang lebih besar untuk patuh terhadap SOP dibandingkan dengan yang berpengetahuan kurang. Damayanti, dkk (2015) juga melakukan penelitian dengan hasil yang menyatakan bahwa pengetahuan memiliki hubungan yang signifikan dengan kepatuhan alat pelindung diri. Hal tersebut sesuai dengan Notoatmodjo (2007) yang menyatakan bahwa pengetahuan merupakan dasar pembentukan perilaku seseorang. Oleh karena itu, pekerja dengan pengetahuan yang baik dapat mencegah terjadinya kecelakaan kerja baik pada dirinya maupun orang lain.

Berdasarkan hasil penelitian di proyek konstruksi Tunjungan Plaza 6 Surabaya, pengetahuan merupakan faktor yang memiliki hubungan dengan kepatuhan pekerja terhadap SOP bekerja di ketinggian. Hasil penelitian ini dapat dijadikan rekomendasi untuk perusahaan agar menambah pengetahuan bagi pekerja tentang SOP bekerja di ketinggian terlebih dahulu sebelum para pekerja melakukan pekerjaan mereka. Pekerja yang memiliki pengetahuan baik akan lebih mudah diarahkan untuk mematuhi SOP bekerja di ketinggian sehingga budaya keselamatan bisa terbentuk dan bisa mengurangi risiko terjadinya kecelakaan kerja.

\section{Kepribadian}

Geller (2001) dalam teori safety triad mengemukakan bahwa terdapat beberapa komponen yang saling berkaitan dalam membentuk budaya keselamatan. Komponen tersebut yaitu person, behavior, dan environment. Salah satu faktor dalam komponen person yaitu kepribadian sehingga akan berkaitan dengan perilaku kepatuhan terhadap SOP bekerja di ketinggian. Kepribadian A cenderung merasa tidak sabar, selalu bergerak cepat, tidak suka menghabiskan banyak waktu untuk bersantai, dan sering merasa tidak sabar. Sedangkan kepribadian B cenderung tidak terlalu suka berkompetisi, lebih suka menghabiskan waktu untuk bersantai, dan berorientasi memperoleh kegembiraan.

Penelitian yang dilakukan di proyek konstruksi Tunjungan Plaza 6 Surabaya tidak dapat membuktikan hipotesis bahwa terdapat hubungan antara kepribadian dengan kepatuhan terhadap SOP bekerja di ketinggian. Hasil penelitian di lapangan menyatakan bahwa tidak ada hubungan yang signifikan antara tipe kepribadian dengan kepatuhan SOP bekerja di ketinggian. Meskipun tidak ada hubungan yang signifikan namun tipe kepribadian A memiliki persentase sedikit lebih besar untuk patuh terhadap SOP bekerja di ketinggian daripada tipe kepribadian B. Persentase kepatuhan tipe kepribadian A yang lebih besar dibandingkan tipe kepribadian $B$ karena tipe kepribadian A mempunyai sifat yang perfeksionis dan akan merasa tidak sempurna jika tidak patuh SOP bekerja di ketinggian.

Hasil penelitian ini tidak sejalan dengan penelitian Haqi (2013) yang menyatakan bahwa tipe kepribadian A cenderung melakukan unsafe action karena tipe kepribadian A sering terburuburu dalam melakukan pekerjaan sehingga lebih ceroboh dan tidak patuh terhadap SOP bekerja di ketinggian. Hal tersebut sesuai dengan Anderson, dkk (2005) yang menyatakan bahwa kepribadian tipe A sering mengalami kejadian kecelakaan kerja. 
Terdapat beberapa cara untuk mengukur kepribadian, diantaranya dengan menggunakan wawancara dan kuesioner. Penelitian pada pekerja pemasangan kaca PT Sri Murni di proyek konstruksi Tunjungan Plaza 6 Surabaya menggunakan cara kuesioner untuk mengetahui kepribadian pekerja. Cara pengukuran kepribadian mungkin kurang maksimal karena hanya menggunakan kuesioner tanpa wawancara sehingga tidak didapatkan data mendalam tentang kepribadian pekerja.

\section{Komunikasi}

Komunikasi merupakan salah satu faktor dalam komponen behavior pada teori safety triad. Menurut Geller (2001) dalam teori safety triad, komunikasi berkaitan dengan kepatuhan sehingga komunikasi seharusnya memiliki hubungan dengan perilaku kepatuhan terhadap SOP bekerja di ketinggian.

Penelitian pada pekerja PT Sri Murni di proyek konstruksi Tunjungan Plaza 6 Surabaya berhasil membuktikan hipotesis tersebut karena hasil penelitian menyatakan bahwa terdapat hubungan yang signifikan antara komunikasi dengan kepatuhan SOP bekerja di ketinggian, dan memiliki nilai koefisien kontingensi 0,418. Bila dibandingkan dengan tabel 1 tentang koefisien kontingensi, kuat hubungan antara komunikasi dengan kepatuhan SOP bekerja di ketinggian adalah sedang. Hal ini terbukti karena pekerja yang memiliki komunikasi baik lebih banyak yang patuh terhadap SOP bekerja di ketinggian dibandingkan pekerja dengan komunikasi kurang.

Hasil penelitian tersebut tidak sejalan dengan penelitian yang dilakukan Haqi (2013) yang menyatakan bahwa tidak ada pengaruh antara komunikasi dengan terjadinya unsafe action. Komunikasi merupakan rangsangan yang berupa lisan maupun gerakan yang akan memengaruhi orang lain (Notoatmodjo, 2003). Adanya hubungan antara komunikasi dengan kepatuhan SOP karena rangsangan yang diberikan sesama pekerja maupun dari pihak lain mampu membuat pekerja patuh terhadap SOP bekerja di ketinggian. Hasil penelitian ini dapat dijadikan rekomendasi untuk perusahaan agar tetap mempertahankan komunikasi yang terjalin antar pekerja dan juga komunikasi pekerja dengan pihak lain seperti supervisor atau pihak safety, karena komunikasi yang baik juga akan meningkatkan kepatuhan pekerja terhadap SOP bekerja di ketinggian sehingga mengurangi risiko kecelakaan kerja yang mungkin terjadi dan meningkatkan keselamatan para pekerja.

\section{Pengawasan HSE atau Pihak Safety}

Pengawasan dilakukan untuk memastikan bahwa tujuan dan target sesuai dengan kebutuhan, memastikan pekerja dapat menanggulangi kesulitan yang mereka temui, meningkatkan motivasi, membantu meningkatkan keterampilan dan kemampuannya (Geller, 2001). Menurut Halimah (2010), peran pengawas merupakan faktor yang paling dominan yang berhubungan dengan perilaku pekerja. Pengawasan pekerjaan pemasangan kaca di proyek konstruksi Tunjungan Plaza 6 Surabaya dilakukan oleh pihak safety PT Sri Murni. Oleh karena itu, ketika pihak safety kurang melakukan pengawasan maka pekerja akan cenderung berperilaku tidak aman.

Penelitian pada pekerja pemasangan kaca PT Sri Murni di proyek konstruksi Tunjungan Plaza 6 Surabaya tidak dapat membuktikan hipotesis tersebut, karena hasil penelitian menunjukkan bahwa tidak ada hubungan yang signifikan antara pengawasan pihak safety dengan kepatuhan pekerja terhadap SOP bekerja di ketinggian. Hal tersebut sejalan dengan penelitian dari Nurvita (2015) yang menyatakan tidak ada hubungan antara peran pengawasan dengan kepatuhan pelaporan bahaya. Saputri dan Indriati (2014) juga menyatakan bahwa tidak ada hubungan antara pengawasan pihak K3 atau safety dengan kepatuhan penggunaan APD pekerja.

Hasil tersebut berbanding terbalik dengan penelitian Hayati (2004) yang dapat membuktikan bahwa terdapat hubungan antara pengawasan dengan tingkat kepatuhan terhadap pelaksanaan SOP pada pekerja welding. Penelitian yang dilakukan oleh Candra (2015) juga menunjukkan hasil terdapat hubungan yang signifikan antara pengawasan dengan kepatuhan penggunaan APT di Unit Pemeliharaan PLTD Ampenan PT PLN (Persero) Sektor Pembangkitan Lombok.

Tidak adanya hubungan antara pengawasan pihak safety dengan kepatuhan SOP bekerja di ketinggian bisa terjadi karena beberapa kemungkinan, antara lain karena pekerja mengisi kuesioner tidak sesuai dengan kondisi aktual di lapangan sehingga kualitas data yang diperoleh tergantung dari motivasi pekerja pada saat pengisian kuesioner dilakukan. Hasil penelitian yang tidak sesuai dengan teori ini bisa disebabkan karena adanya pengaruh dari faktor lain seperti sikap dan pengaruh rekan kerja. Namun, menurut wawancara dengan pihak safety, pengawasan tidak dilakukan 
setiap hari melainkan hanya beberapa kali dalam seminggu. Hal tersebut bisa menjadi salah satu faktor yang menyebabkan tidak adanya hubungan antara pengawasan pihak safety dengan kepatuhan SOP bekerja di ketinggian.

\section{SIMPULAN}

Penelitian pada pekerja pemasangan kaca PT Sri Murni di proyek konstruksi Tunjungan Plaza 6 Surabaya dapat disimpulkan bahwa sebagian besar pekerja memiliki pengetahuan baik tentang SOP bekerja di ketinggian, sebagian pekerja juga memiliki komunikasi yang baik antar pekerja maupun pekerja dengan supervisor. Jumlah pekerja dengan tipe kepribadian A dan pekerja dengan tipe kepribadian B hampir sama. Sebagian besar pekerja juga telah patuh terhadap SOP bekerja di ketinggian.

Uji kuat hubungan antara faktor person, behavior, dan environment didapatkan hasil variabel pengetahuan yang merupakan salah satu komponen dalam faktor person dan variabel komunikasi yang merupakan salah satu komponen dalam behavior yang memiliki hubungan sedang dengan kepatuhan terhadap SOP bekerja di ketinggian.

Berdasarkan penelitian yang telah dilakukan, maka saran yang dapat diberikan kepada pihak perusahaan PT Sri Murni dalam upaya meningkatkan dan mempertahankan kepatuhan pekerja terhadap SOP bekerja di ketinggian yaitu melalui pengadaan training atau safety talk secara rutin untuk meningkatkan pengetahuan pekerja. Pihak safety harus lebih mengawasi pekerja dalam melaksanakan pekerjaannya, agar pekerja bisa lebih patuh dalam menerapkan SOP bekerja di ketinggian. Komunikasi yang terjalin antar pekerja dan komunikasi antara pekerja dengan supervisor atau pihak safety agar dipertahankan misalnya saling mengingatkan untuk selalu berperilaku selamat.

\section{DAFTAR PUSTAKA}

Anderson, N., Ones, D.S., Sinangil, H.K., Viswesvaran, Chockalingam. 2005. Handbook of Industrial, Work and Organizational Psychology. London: SAGE Publications Company.

Candra, A. 2015. Hubungan Faktor Pembentuk Perilaku dengan Kepatuhan Penggunaan Alat Pelindung Telinga pada Tenaga Kerja di PLTD Ampenan. The Indonesian Journal of
Occupational Safety and Health, 4(1), pp. 90 [e-journal] terdapat di http://journal.unair.ac.id diakses pada tanggal 14 Juli 2017.

Dahlan, M.S. 2001. Statistik untuk Kedokteran dan Kesehatan. Jakarta: Salemba Medika.

Darmayanti, Dewa A.A.I., Ketut Tirtayasa, I Kadek Saputra. 2015. Hubungan antara Tingkat Pengetahuan dengan Kepatuhan dalam Menggunakan Alat Pelindung Diri pada Petani Pengguna Pestisida. COPING Ners Journal, 3(3), pp. 73-74 [e-journal] terdapat di http:// download.portalgaruda.org diakses pada tanggal 14 Juli 2017.

Geller, E.S. 2001. The Psychology of Safety Handbook. New York : Lewis Publishers.

Halimah, S. 2010. Faktor-faktor yang Memengaruhi Perilaku Aman Karyawan di Area Produksi PT SIM Plant Tambun II Tahun 2010. Skripsi. Jakarta: FKIK Universitas Islam Negeri Syarif Hidayatullah.

Hayati. 2004. Hubungan Faktor Internal dan Eksternal Tingkat Kepatuhan terhadap Pelaksanaan SOP pada Pekerja Bagian Welding PT Krama Yudha Ratu Motor. Skripsi. Depok: FKM Universitas Indonesia.

Haqi, D.N. 2013. Analisis Penyebab Unsafe Action dengan Pendekatan Human Factors and Classification System (HFACS). Tesis. Surabaya: FKM Universitas Airlangga.

Judha, M. 2012. Hubungan Tingkat Pengetahuan Perawat dengan Kepatuhan dalam Pelaksanaan SOP Pemasangan Kateter Urin di Bangsal Rawat Inap RSUD Panembahan Senopati Bantul.

Ministry of Manpower, the Workplace Safety and Health Council, the National Work at Height Safety Taskforce. 2011. Safety Analysis and Recommendation Report on Work At Height: A Study of 126 Falls from Height (FFH) cases: Singapore.

Nurvita, D. 2015. Faktor-faktor yang Berhubungan dengan Kepatuhan Pelaporan Bahaya pada Pekerja Teknisi Unit Maintenance di PT Pelita Air Service Area Kerja Pondok Cabe, Tangerang Selatan. Skripsi. Jakarta: FKIK UIN Syarif Hidayatullah.

Notoatmodjo, S. 2003. Pendidikan dan Perilaku Kesehatan. Jakarta: Rineka Cipta.

Notoatmodjo, S. 2007. Promosi Kesehatan dan Ilmu Perilaku. Jakarta: Rineka Cipta.

Saputri, I., Indriati, P. 2014. Faktor-faktor yang Berhubungan dengan Kepatuhan Penggunaan 
APD pada Pekerja Kerangka Bangunan. The Indonesian Journal of Occupational Safety and Health Vol. 1 [e-journal] terdapat di http:// journal.unair.ac.id diakses pada tanggal 14 Juli 2017.
Zalaya, Y. 2012. Implementasi Prosedur Bekerja di Ketinggian di PT. BBS Indonesia (WTC 2 Project). Tesis. Depok: Universitas Indonesia. 